\title{
Left cervical aortic arch associated with aortic aneurysm
}

\author{
TERENCE MORRIS AND MICHAEL RUTTLEY \\ From the Departments of Cardiology and Radiology, University Hospital of Wales, Heath Park, Cardiff
}

An aortic arch extending into the neck is a rare congenital anomaly. Left-sided cervical aortic arch was thought to be much less common than right-sided, but they are now almost equal in incidence in the published reports. This paper describes a case of left-sided cervical aortic arch in an adult, with a previously undescribed association, aneurysm of the descending thoracic aorta. Cervical aortic arch must be considered in the differential diagnosis of pulsatile cervical swellings. The embryological development of the aortic arch is discussed. This is still controversial and it is not possible to be sure of the embryological explanation of this congenital anomaly of the aortic arch from a study of the adult anatomy.

An aortic arch extending into the neck is a rare congenital anomaly. Only 11 cases of left cervical aortic arch have been described (Mahoney and Manning, 1964; Sissman, 1968; De Jong and Klinkhamer, 1969; Yigitbasi and Nalbantgil, 1971; McCue et al., 1973; DuBrow et al., 1974; Moncada et al., 1975). The purpose of this report is to add a further case with a previously undescribed association, aneurysm of the descending thoracic aorta.

\section{Case report}

The patient is a white woman born in 1942. A heart murmur was detected at birth but she developed normally and did not present until the age of 16 years, when she complained of mild dyspnoea on effort. Examination at that time showed pronounced arterial pulsation in the left side of the neck, extending from the supraclavicular fossa to the level of the cricoid cartilage. The left radial and both femoral pulses were reduced in volume but not delayed. Blood pressure was $150 / 100 \mathrm{mmHg}$ in the right arm, $130 / 80 \mathrm{mmHg}$ in the left arm. The apex beat was not displaced and the cardiac impulse was normal. A loud ejection systolic murmur was best heard at the left sternal edge and was conducted into the left side of the neck.

The electrocardiogram showed left axis deviation and left ventricular preponderance. Chest $x$-ray, mediastinal tomography, and barium swallow were reported to show cardiac enlargement, a widened aortic arch with three convex shadows in the left superior mediastinum, and an abnormal impression on the left lateral and posterior margins of the oesophagus at the level of the aortic arch. Further investigation was declined.

Apart from hypertension with each of two otherwise normal pregnancies, she remained well until 1974 when she presented with dysphagia and agreed to further investigation. The physical signs were unchanged from those recorded in 1958. Electrocardiogram was normal with QRS axis $-30^{\circ}$. Chest $x$-ray film showed a large left superior mediastinal mass with a thin line of calcification at its lateral margin. Cardiothoracic ratio was 50 per cent (Fig. 1). Barium swallow showed oesophageal compression from the left at supraclavicular, aortic arch, and low thoracic levels but only minimal holdup of barium at these sites. At cardiac catheterization haemodynamic data were normal except for a gradient of $20 \mathrm{mmHg}$ between ascending aorta and distal descending thoracic aorta.

Aortography showed a dilated ascending aorta with normal right brachiocephalic artery and left common carotid artery. Immediately distal to the left common carotid artery the aortic arch made a right-angle bend to pass into the left side of the neck, almost to the level of the cricoid cartilage (Fig. 2a). The aorta made several further acute bends in the neck and gave rise to the left subclavian artery. It then passed back into the thorax and after two more acute bends dilated into a large aneurysm of the descending thoracic aorta (Fig. 2b). The aorta 
was of normal calibre but tortuous below the aneurysm.

\section{Discussion}

Left cervical aortic arch was thought to be more rare than right, but they are now of almost equal incidence (Moncada et al., 1975). The present case is certainly the most bizarre and the only one associated with an aortic aneurysm, though some cases are associated with cardiac abnormalities such as

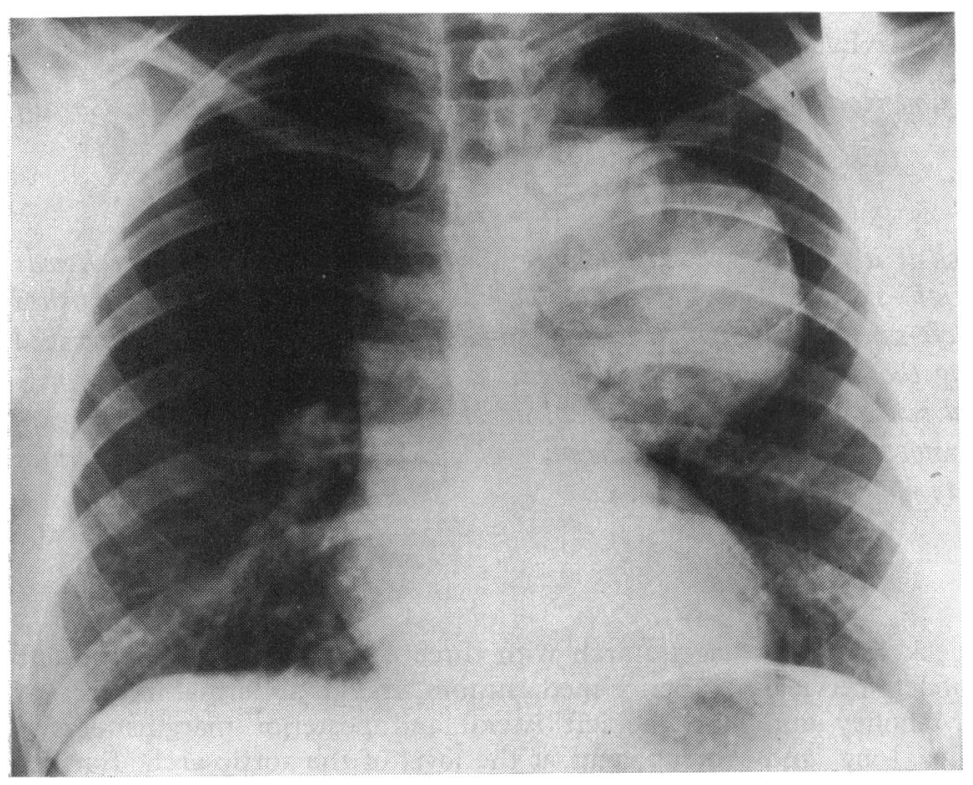

Fig. 1 Posteroanterior chest $\mathrm{x}$-ray film showing large left superior mediastinal mass with line of calcification at edge.

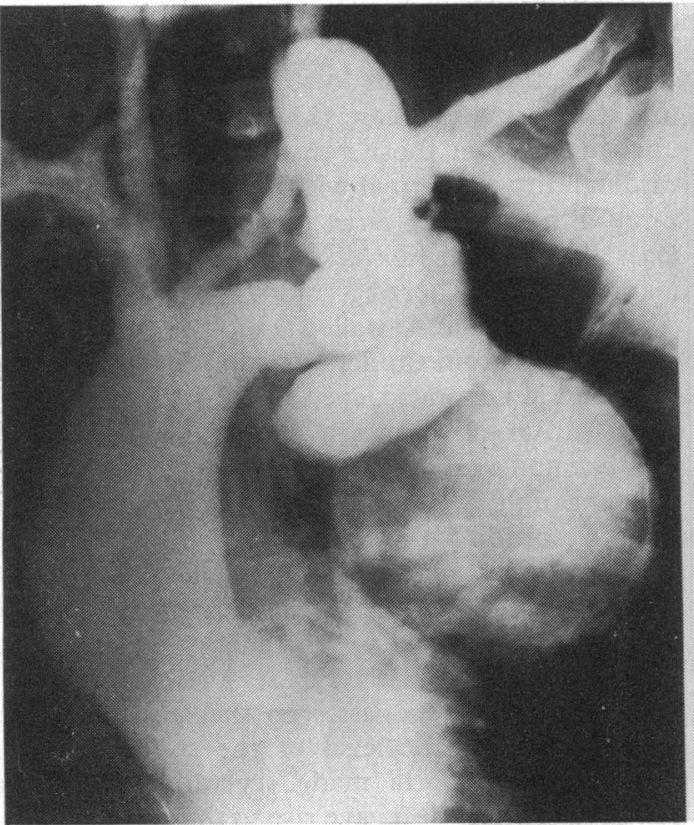

a

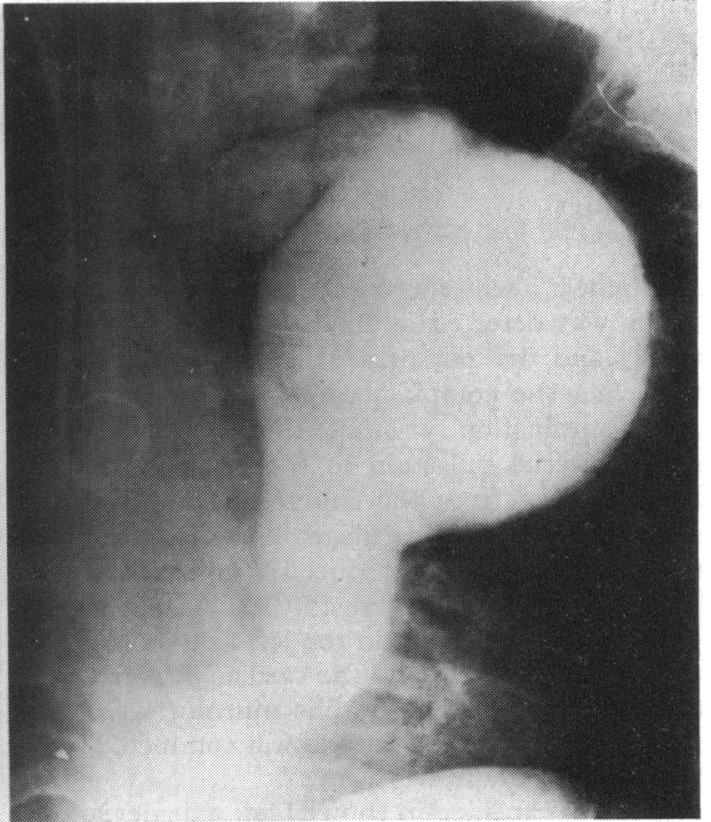

$\mathrm{b}$

Fig. 2 Films from the aortogram showing the left cervical aortic arch (a) and associated aneurysm of descending thoracic aorta (b). 
tetralogy of Fallot and pseudotruncus arteriosus (Moncada et al., 1975). The large aneurysm may be secondary to the haemodynamic disturbance produced by the very tortuous aorta. A similar situation arises in so-called 'kinked aorta' or pseudocoarctation (Stevens, 1958; Pattinson and Grainger, 1959; Smyth and Edwards, 1972). Edwards (1973) describes the formation of thoracic aortic aneurysm in coarctation, suggesting bacterial endarteritis and dissection as the mechanisms involved. The dilatation of this patient's ascending aorta is difficult to explain: though it resembles post-stenotic dilatation, there was no aortic valve disease.

The embryological explanation of cervical aorta is not clear. The aortic arch has a complex development which cannot be adequately represented by the traditional Rathke diagram. There is still much disagreement about the contribution of the various elements of the branchial arch system to the adult aortic arch and its major branches. The proximal ascending aorta develops from the primitive aortic sac caudal to the 4th branchial arch. The 4th arch itself is variously described as contributing to the descending aorta (Congdon, 1922) and the ascending aorta (Hammond, 1937). Moffat (1959) studied the development of the aortic arch system in the rat and believed that the 4 th arch contributed to the ascending aorta proximal to the left common carotid. Barry (1951) described the left 4th arch artery as forming only the adult aortic isthmus between the left common carotid and the left subclavian.

There is also disagreement about the origin of the branches of the aortic arch. The right 4th arch contributes to the innominate artery. The common carotid may be formed from the 3rd arch as described by Congdon (1922), Hammond (1937), and Padget (1948), but other suggestions include the ventral aorta (Ito, 1940) and the ventral aortic root (Barry, 1951).

Llorca (1934) believes that the common carotid artery is formed by fusion of the internal and external carotid arteries. Moffat (1959) believes that in most cases the common carotid artery is formed as a result of the elongation of the cranial portion of the aortic sac and that the 3rd arch artery forms only the proximal portion of the internal carotid artery, but admits that in some cases Congdon's suggestion may be true.

The left subclavian artery develops from the 7th postcranial intersegmental artery. Development of the adult pattern involves considerable relative shortening of the primitive aortic arch and descent into the thorax associated with development of the neck. The left subclavian artery reaches its adult position by a process of relative and actual migration along the primitive aorta (Moffat, 1960).
These studies indicate that it is difficult to determine the embryological origin of an aortic arch anomaly by a study of its anatomy or the arrangement of the cerebral vessels. Mahoney and Manning (1964) described a case similar to ours and suggested that it represented formation of the aortic arch from the 2nd branchial arch. A similar suggestion has been made by Shuford et al. (1972). Beavan and Fatti (1947) and Harley (1959) described cases of right cervical aortic arch which they believed were a result of the adult aortic arch developing from the 3rd branchial arch artery. We agree with DuBrow et al. (1974) when they suspect different aetiologies for various cervical aortic anomalies. We suggest that our case represents formation of the aortic arch either partly from the 3rd left branchial arch artery or by anomalous development of the left 4th arch artery with failure of normal descent into the thorax.

Clinically the importance of these anomalies is that they enter into the differential diagnosis of pulsating supraclavicular masses and may be mistaken for aneurysm of the innominate or carotid artery. A case of right cervical aorta was recently referred to this department for 'carotid arteriography prior to ligation of right carotid aneurysm' and one fatality resulting from such a mistake has been recorded (Beavan and Fatti, 1947).

Difficulties in diagnosis should not arise if both radial and femoral pulses are felt in all cases of suspected innominate or carotid artery aneurysm. The chest $x$-ray film may suggest the diagnosis and aortography will supply details of the anatomy. DuBrow et al. (1974) operated successfully on their patient. We doubt in our case if an attempt at surgical correction of such an extensive lesion is justified at present as her only symptom, dysphagia, is now slight. Further enlargement of the aneurysm may become an indication for surgery and the patient is, therefore, being followed up by periodic chest $x$-ray examination.

We thank Dr. A. J. Thomas for permission to report this case and Professor D. B. Moffat for advice.

\section{References}

Barry, A. (1951). The aortic arch derivatives in the human adult. Anatomical Record, 111, 221.

Beavan, T. E. D., and Fatti, L. (1947). Ligature of the aortic arch in the neck. British fournal of Surgery, 34, 414.

Congdon, E. D. (1922). Transformation of the aortic-arch system during development of the human embryo. Contributions to Embryology, 14, 47.

De Jong, I. H., and Klinkhamer, A. C. (1969). Left-sided cervical aortic arch. American fournal of Cardiology, 23, 285.

DuBrow, I. W., Burman, S. D., Elias, D. O., Hastreiter, A. R., and Pietras, R. J. (1974). Aortic arch in the neck. Fournal of Thoracic and Cardiovascular Surgery, 68, 21. 
Edwards, J. E. (1973). Aneurysms of the thoracic aorta complicating coarctation. Circulation, 48, 195.

Hammond, W. S. (1937). The developmental transformation of the aortic arches in the calf (Bos taurus) with special reference to the formation of the arch of the aorta. American Fournal of Anatomy, $62,149$.

Harley, H. R. S. (1959). The development and anomalies of the aortic arch and its branches. British fournal of Surgery, 46, 561 .

Ito, T. (1940). Studien über die Entwicklung des Aortenborgens und seiner Aste bei den Mammalien, besonders bei mans embryonen (abstract of Japanese text). Fournal of the Okayama Medical Society, 52, 1912.

Llorca, F. O. (1934). Uber die Entwicklung des Arterienbogen buim Schwein. Zeitschrift für Anatomie und Entwicklungsgeschichte, 102, 335.

McCue, C. M., Mauck, H. P., Jr., Tingelstad, J. B., and Kellett, G. N., Jr. (1973). Cervical aortic arch. American Fournal of Diseases of Children, 125, 738.

Mahoney, E., and Manning, J. A. (1964). Congenital abnormalities of the aortic arch. Surgery, 55, 1.

Moffat, D. B. (1959). Developmental changes in the aortic arch system of the rat. American fournal of Anatomy, $105,1$.

Moffat, D. B. (1960). Pre- and post-natal changes in the left subclavian artery and their possible relationship to coarctation of the aorta. Acta Anatomica, 43, 346.
Moncada, R., Shannon, M., Miller, R., White, H., Friedman, J., and Shuford, W. H. (1975). The cervical aortic arch. American fournal of Roentgenology, 125, 591.

Padget, D. H. (1948). Development of the cranial arteries in the human embryo. Contributions to Embryology, 32, 205.

Pattinson, J. N., and Grainger, R. G. (1959). Congenital kinking of the aortic arch. British Heart fournal, 21, 555.

Shuford, W. H., Sybers, R. G., Milledge, R. D., and Brinsfield, D. (1972). The cervical aortic arch. American fournal of Roentgenology, 116, 519.

Sissman, N. J. (1968). Anomalies of the aortic arch complex. In Heart Disease in Infants, Children and Adolescents, p. 414. Ed. by A. J. Moss and F. H. Adams. Williams and Wilkins, Baltimore.

Smyth, P. T., and Edwards, J. E. (1972). Pseudocoarctation, kinking or buckling of the aorta. Circulation, 46, 1027.

Stevens, G. M. (1958). Buckling of the aortic arch (pseudocoarctation, kinking). A roentgenographic entity. Radio$\log y, 70,67$.

Yigitbasi, O., and Nalbantgil, I. (1971). Murmur over an abnormal left apical mass. Chest, 59, 561.

Requests for reprints to Dr. T. J. Morris, Llandough Hospital, Penarth, Nr. Cardiff, South Glamorgan. 